\title{
Mutational Mtc6p attenuates autophagy and improves secretory expression of heterologous proteins in Kluyveromyces marxianus
}

Yang Liu ${ }^{1,2}$, Wen-Juan Mo ${ }^{1,2}$, Tian-Fang Shi ${ }^{1,2}$, Meng-Zhu Wang ${ }^{1,2}$, Jun-Gang Zhou ${ }^{1,2}$, Yao Yu ${ }^{1,2}$, Wen-Shan Yew ${ }^{3,4}$ and Hong $\mathrm{Lu}^{1,2^{*}}$

\begin{abstract}
Background: The yeast Kluyveromyces marxianus is an emerging cell factory for heterologous protein biosynthesis and its use holds tremendous advantages for multiple applications. However, which genes influence the productivity of desired proteins in K. marxianus has so far been investigated by very few studies.

Results: In this study, we constructed a K. marxianus recombinant (FIM1/Est1E), which expressed the heterologous ruminal feruloyl esterase Est1E as reporter. UV- ${ }^{60} \mathrm{Co}-\gamma$ irradiation mutagenesis was performed on this recombinant, and one mutant (be termed as T1) was screened and reported, in which the productivity of heterologous Est1E was increased by at least tenfold compared to the parental FIM1/Est1E recombinant. Transcriptional perturbance was profiled and presented that the intracellular vesicle trafficking was enhanced while autophagy be weakened in the T1 mutant. Moreover, whole-genome sequencing combined with CRISPR/Cas9 mediated gene-editing identified a novel functional protein Mtc6p, which was prematurely terminated at Tyr251 by deletion of a single cytosine at 755 loci of its ORF in the T1 mutant. We found that deleting C755 of MTC6 in FIM1 led to 4.86-fold increase in the production of Est1E compared to FIM1, while the autophagy level decreased by 47\%; on the contrary, when reinstating C755 of MTC 6 in the T1 mutant, the production of Est1E decreased by $66 \%$ compared to T1, while the autophagy level increased by $124 \%$. Additionally, in the recombinant with attenuated autophagy (i.e., FIM1 mtc6 ${ }^{\mathrm{C} 755 \Delta}$ and T1) or interdicted autophagy (i.e., FIM1 atg $1 \triangle$ and $T 1 \operatorname{atg} 1 \Delta$ ), the productivity of three other heterologous proteins was also increased, specifically the heterologous mannase Man330, the $\beta$-1,4-endoxylanase XynCDBFV or the conventional EGFP.
\end{abstract}

Conclusions: Our results demonstrated that Mtc6p was involved in regulating autophagy; attenuating or interdicting autophagy would dramatically improve the yields of desired proteins in K. marxianus, and this modulation could be achieved by focusing on the premature mutation of Mtc6p target.

Keywords: Kluyveromyces marxianus, Heterologous protein expression, Autophagy, MTC6, Ruminal feruloyl esterase

\footnotetext{
*Correspondence: honglv@fudan.edu.cn

1 State Key Laboratory of Genetic Engineering, School of Life Science,

Fudan University, Shanghai 200438, People's Republic of China

Full list of author information is available at the end of the article
} 


\section{Background}

Kluyveromyces marxianus is a generally regarded as safe (GRAS) ascomycetous yeast that has advantageous properties for multiple applications. $K$. marxianus has been employed as a host for synthesizing a number of heterologous agro-industrial and pharmaceutical proteins, such as the GOX, the $\mathrm{Cu} / \mathrm{Zn} \mathrm{SOD}$ and the Dengue virus type 1 NS1 [1-3]. However, the maximum reported yields of these proteins produced by $K$. marxianus are still within the range of milligrams per litre and require substantial improvements before sustainable industrial utility can be attained [4-6].

Accumulating evidences indicate that the translational and post-translational efficiency and/or the vesicle trafficking capacity play an important role in the expression of membrane or secretory proteins [7]. However, protein target to secretory pathways often suffer from secretion saturation $[8,9]$. Strategies, such as engineering protein folding or modulating vesicular trafficking, have been carried out in S. cerevisiae or P. pastoris to improve the production of desired proteins $[10,11]$. For instance, many chaperones or redox enzymes, such as the chaperone $\mathrm{BiP}$ or the protein disulfide isomerase Pdilp, have been used to assist protein folding; some components, such as the SNAREs elements which are engaged in the ER-to-Golgi trafficking, have been modulated and modified to increase the secretory expression of desired proteins.

Generally, anterograde transport of the correctly folded precursor proteins from ER to cis-Golgi are carried by the COPII-coated vesicles, which are mainly organized by Sar1p, Sec16p, Sec23p/Sec24p and Sec13p/Sec31p, and budding at the ER exit sites (ERES) [7]. The ER can also act as the primary site for autophagosome biogenesis, and some interactions between the constituents of ERES and the Atg machinery have been identified [12, 13]. For instance, the Atg1p, an essential kinase in initiating and regulating autophagy, could phosphorylate Sec23Ap and reduce cargo export at the ERES, while it could also phosphorylate Sec16p and modulate the morphology of ERES $[14,15]$. Besides, formation of the pre-autophagosomal structures (PAS) requires both COPI and COPII vesicles, in which some components of the COPII vesicles (e.g., Sar1p, Sec24p and Ypt1p/Rab1p) serve as multitasking proteins in the secretion and autophagy cross-talk [16]. However, in the previous studies, the equilibrium and interactions between autophagy and secretion of proteins have been largely neglected in most engineering efforts for improving the yields of desired proteins from these eukaryotic expression systems, and the complex protein secretory pathway in $K$. marxianus remains elusive.

Here, we aimed to improve the yields of desired proteins expressed in $K$. marxianus using the conventional irradiation mutagenesis, and attempted to optimize the strategies for yeast engineering by identifying the major genetic determinants, which play an important role in regulating the productivity of desired proteins in $K$. marxianus.

\section{Methods}

\section{Strains and cultivations}

All the strains and mutants used in this work were described in Table 1 . The patent $K$. marxianus FIM1 strain (CGMCC No. 10621) was employed, which has been deposited in the China General Microbiological Culture Collection Center (CGMCC). Yeast cells were routinely cultivated in complex YPD medium $(10 \mathrm{~g} / \mathrm{L}$ yeast extract, $20 \mathrm{~g} / \mathrm{L}$ hipolypepton and $20 \mathrm{~g} / \mathrm{L}$ glucose), and the recombinants were screened from the synthetic SD-URA medium (10 g/L glucose, $6.7 \mathrm{~g} / \mathrm{L}$ yeast nitrogen base, $40 \mathrm{mg} / \mathrm{L}$ histidine, $40 \mathrm{mg} / \mathrm{L}$ leucine and $40 \mathrm{mg} / \mathrm{L}$ tryptophan) without uracil due to its intrinsic auxotrophy (ura3 $\Delta$ ). For solid media, 2\% agar was added. For protein production, the recombinants were cultured in $50 \mathrm{~mL}$ of 24-medium ( $20 \mathrm{~g} / \mathrm{L}$ yeast extract and $40 \mathrm{~g} / \mathrm{L}$ glucose $)$ in Erlenmeyer flasks for $96 \mathrm{~h}$ at $30{ }^{\circ} \mathrm{C}, 220 \mathrm{rpm}$, unless special emphasized. The E. coli strain DH5 $\alpha$ was utilized for plasmid propagation and maintenance, which were grown in Luria-Bertani medium supplemented with $100 \mu \mathrm{g} / \mathrm{mL}$ of ampicillin when necessary.

\section{Recombination and gene-editing}

For heterologous expression in $K$. marxianus, the heterologous genes (such as Est1E, Man330, XynCDBFV or $E G F P)$ were amplified and assembled into the pUKDN112 plasmid containing URA3 as biomarker, in which expression of heterologous genes could been driven by the K. marxianus INU1 promoter, secretory signal peptide and terminator. For genomic engineering (such as deletion, directed mutation or insertion) in $K$. marxianus, the CRISPR/Cas9 plasmids were constructed using the pUKD-N122-AUC plasmid as backbone, which synchronously expressed the Cas 9 endonuclease and the sgRNAs. The matched donor sequences could also be designed, amplified and co-transformed with its corresponding CRISPR/Cas9 plasmid. Transformation of the indicated plasmids and/or oligonucleotide fragments into K. marxianus was mediated by LiAc/carrier ssDNA/PEG according to the reports with minor modifications $[17$, 18 ]. All the primers and DNA sequences were listed in Additional file 1: Table S2.

\section{Quantification of recombinant proteins}

In this work, the yields of desired proteins was measured by the specific enzymatic activity or autofluorescence. For quantifying the extracellular proteins, the samples 
Table 1 K. marxianus strains and mutants used in this study

\begin{tabular}{|c|c|c|}
\hline Names & Genotypes or descriptions & Sources \\
\hline FIM1 & ura3 $\triangle$ & This lab \\
\hline $\mathrm{T} 1$ & ura3 $\Delta$; efficiently secrete and express the desired proteins & This study \\
\hline FIM1 cms $1 \Delta$ & ura $3 \triangle \mathrm{cms} 1 \triangle$ & This study \\
\hline FIM1 idp1 $\triangle$ & ura3 $\triangle i d p 1 \triangle$ & This study \\
\hline FIM1 cda2 $\Delta$ & ura3 $\triangle c d a 2 \Delta$ & This study \\
\hline FIM1 hrd3 $\triangle$ & ura3 $\triangle$ hrd3 $\Delta$ & This study \\
\hline FIM1 ynr021w & ura3 $\triangle$ ynr021w $\Delta$ & This study \\
\hline FIM1 mtc $6^{721-903 \Delta}$ & ura3 $\Delta m t c 6^{721-903 \Delta}$ & This study \\
\hline FIM1 mtc6 $6^{\mathrm{C} 755 \Delta}$ & ura3 $\triangle$ mtc $^{\mathrm{C}} \mathrm{755}$; mimic the frameshift mutation of MTC6 in T1 mutant & This study \\
\hline FIM1 mtc6 $6^{754-1773 \Delta}$ & ura3 $\Delta$ mtc $^{754-1773 \Delta}$; resulting in premature termination at Ser252 of Mtc6p & This study \\
\hline FIM1 mtc6 ${ }^{\mathrm{S} 252 *}$ & ura3 $\Delta m$ mtc $^{\mathrm{C} 755 \mathrm{~A} / 7756 \mathrm{~A}}$; resulting in premature termination at Ser252 of Mtc $6 \mathrm{p}$ & This study \\
\hline FIM1 mtc6 $6^{\mathrm{G} 59 \mathrm{~A}}$ & ura3 $\triangle$ mtc $^{659 A}$; resulting in premature termination at Cys 19 of Mtc6p & This study \\
\hline FIM1 sskid & ura3 $\triangle$ ssk $1 \Delta$ & This study \\
\hline FIM1 erf4 $\triangle$ & ura3 $\triangle$ erf $4 \Delta$ & This study \\
\hline FIM1 sea3 $\triangle$ & ura3 $\triangle$ sea3 $\triangle$ & This study \\
\hline FIM1 twf1 $\triangle$ & ura3 $\triangle$ twf1 $\triangle$ & This study \\
\hline FIM1 sea3 $\Delta m t c 6^{721-903 \Delta}$ & ura3 $\triangle$ sea3 $\Delta m t c 6^{721-903 \Delta}$ & This study \\
\hline FIM1 sea3 $\Delta$ mtc $^{721-903 \Delta}$ ynr021w $\Delta$ & ura $3 \Delta$ sea $3 \Delta m_{t c} 6^{721-903 \Delta}$ ynr021w $\Delta$ & This study \\
\hline $\mathrm{FIM} 1 \operatorname{atg} 1 \triangle$ & ura3 $\triangle \operatorname{atg} 1 \triangle$ & This study \\
\hline $\mathrm{T} 1 \operatorname{atg} 1 \triangle$ & ura $3 \triangle$ atg $1 \Delta_{;} \top 1$ mutant as background & This study \\
\hline FIM1 mtc6 $6^{\mathrm{C755 \Delta}}$ atg $1 \Delta$ & ura3 $\Delta \operatorname{mtc} 6^{\mathrm{C} 755 \Delta}$ atg $1 \Delta$ & This study \\
\hline T1 MTC6 & 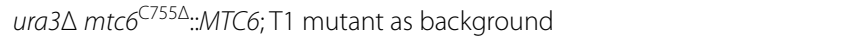 & This study \\
\hline $\mathrm{FIM} 1^{\mathrm{EA}}$ & ura3 $\triangle$ ATG8::EGFP-ATG8 & This study \\
\hline $\mathrm{FIM} 1^{\mathrm{EA}} m t c 6^{\mathrm{C} 755 \Delta}$ & ura3 $\triangle$ ATG8::EGFP-ATG8 mtc6 ${ }^{7755 \Delta}$ & This study \\
\hline $\mathrm{FIM} 1^{\mathrm{EA}}$ atg $1 \triangle$ & ura3 $\triangle$ ATG8::EGFP-ATG8 atg $1 \triangle$ & This study \\
\hline $\mathrm{T} 1{ }^{\mathrm{EA}}$ & ura3 $\triangle$ ATG8::EGFP-ATG8;T1 mutant as background & This study \\
\hline $\mathrm{T}^{\mathrm{EA}} m t c 6^{\mathrm{C} 755 \Delta}$ & 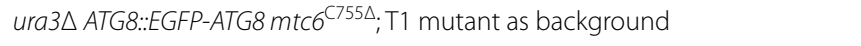 & This study \\
\hline $\mathrm{T} 1^{\mathrm{EA}} \operatorname{atg} 1 \triangle$ & ura3 $\triangle$ ATG8::EGFP-ATG8 atg $1 \triangle ; T 1$ mutant as background & This study \\
\hline
\end{tabular}

were harvested by centrifugation from the fermentation supernatant. Activity of the feruloyl esterase Est1E was detected using a spectrophotometer with 2-chloro-4-nitropheyl ferulate (CNPF) as substrate, which would be catalyzed by feruloyl esterase and release chromophores for quantification [19]. Briefly, the crude Est1E was diluted to optimal concentration with $1 \times$ PBST (pH6.4, T: $2.5 \%$ TritonX-100), and $20 \mu \mathrm{L}$ of each dilution was transferred into $180 \mu \mathrm{L}$ of $1 \mathrm{mM}$ CNPF solution while the 2-chloro-4-nitrophenol was regarded as standards, and the specific absorbance under $410 \mathrm{~nm}$ were detected using a robotic Microplate-reader following incubation at $37{ }^{\circ} \mathrm{C}$ for $10 \mathrm{~min}$. It is worth mentioning that the enzymatic activity unit (U) of Est1E in this work was defined as one nmol of chromophore be released from the substrate per minute under $37^{\circ} \mathrm{C}, \mathrm{pH} 6.4$.

Activity of mannase Man330 or $\beta$-1,4-endoxylanase XynCDBFV was assayed by measuring the amount of reducing sugars released from enzymatic hydrolysis using the dinitrosalicylic method as reported previously
$[20,21]$. Briefly, the $0.3 \%$ locust bean gum ( $\mathrm{pH} 9.5)$ was introduced as substrate for mannase, and the $2 \%$ xylan $(\mathrm{pH} 5.5)$ was used as substrate for $\beta$-1,4-endoxylanase. Of note, the enzymatic activity unit (U) of Man330 or XynCDBFV was defined as the amount of enzyme that produced one $\mu \mathrm{mol}$ of reducing sugar per minute under the suitable temperature and $\mathrm{pH}$.

Moreover, EGFP accumulated in the supernatant was quantified by measuring its fluorescence intensity under excitation wavelength $485 \mathrm{~nm}$ and emission wavelength $525 \mathrm{~nm}$ using a Tecan Infinite multimode reader.

\section{Irradiation mutagenesis and high-throughput screening}

The FIM1/Est1E recombinants in logarithmic phase were harvested and exposed to UV radiation at a distance of $20 \mathrm{~cm}$ for $30 \mathrm{~min}$ using a UV stratalinker $\left(120 \mathrm{~mJ} / \mathrm{cm}^{2}\right)$, followed by cultivation at $30{ }^{\circ} \mathrm{C}, 220 \mathrm{rpm}$ for $1 \mathrm{~h}$ and stored at $4{ }^{\circ} \mathrm{C}$, overnight. All these manipulations were performed away from light and repeated for a week. Then, the treated cells were inoculated into $50 \mathrm{~mL}$ of 
YPD medium and cultivated to logarithmic phase, and exposed to ${ }^{60} \mathrm{Co}-\gamma$ irradiation at a dose of $14.5 \mathrm{kGy} / \mathrm{h}$ for $1 \mathrm{~h}$. The suspension was diluted with $\mathrm{dd}_{2} \mathrm{O}$ and spread onto SD-URA plates to isolate single colony.

For screening the desired mutants, the heterologous feruloyl esterase Est1E was elected as a biomarker and the artificial CNPF was designed as specific substrate applied to high-throughput screening. Shortly, the single colony was inoculated into $600 \mu \mathrm{L}$ of 24-medium in 24-well clusters, and incubated at $30^{\circ} \mathrm{C}, 220 \mathrm{rpm}$ for $96 \mathrm{~h}$. Then, activity of Est1E in the fermentation supernatant was determined as mentioned above.

\section{Genome and transcriptome analyses}

Genomic DNA was extracted using the TIANamp Yeast DNA Kit (TIANGEN\#DP307) according to the manufacturer's instructions, and $2 \mu \mathrm{g}$ of the certified DNA from each sample was submitted for sequencing at the Chinese National Human Genome Center (Shanghai) using the Illumina PET HiSeq technology. The reads were optimized and assembled into eight ungapped contigs with an average coverage of $100 \times$, in turn, a number of SNPs or indels in the mutants against the wild-type strain were identified, then be annotated and assigned by GO and KOG database.

For transcriptome profiling, recombinants were grown in $50 \mathrm{~mL}$ of 24-medium in Erlenmeyer flasks and sampled at the indicated time-points (the 4th, 6th, 12th, 24th, 48th and 72th h over the growth). Total RNA was isolated and purified using the ZR Fungal/Bacterial RNA MiniPrep $^{\text {TM }}$ (ZYMO RESEARCH\#R2014) according to the manufacturer's instructions, and about $10 \mu \mathrm{g}$ of the validated RNA from each sample was submitted for sequencing at Genergy Biotechnology (Shanghai) Co., Ltd using the Illumina HiSeq 3000. Subsequently, 11.6-38.2 million of read pairs were obtained for each sample and the raw reads were mapped to the FIM1 reference genome, with $79.8-96.9 \%$ of the reads successfully mapped. Cuffnorm was used to calculate FPKM values, and the differential expression among two samples was analyzed using $D E S e q 2$, from where the differential expression level of genes ( $\log _{2}$ FoldChange) and corresponding significant levels (adjust $p$-values) were obtained.

\section{SDS-PAGE and western blot assay}

SDS-PAGE and western blot were performed comply with a standard protocol. The cell lysates were prepared using lysis buffer containing the protease inhibitor cocktail (Roche\#04693-159001). The protein bands separated in SDS-PAGE were visualized by Coomassie Brilliant Blue staining, alternatively, signals of the interesting proteins were developed using the specific antibodies and chemiluminescence reagents. The mouse anti-GFP Tag
(7G9) antibody (Abmart\#M20004) was utilized to detect EGFP and/or EGFP-labelled protein, while the mouse anti- $\alpha$-Tubulin antibody (SIGMA\#T6199) was used to detect $\alpha$-tubulin protein in lysates to normalize loading.

\section{Autophagy assay}

Autophagic activity can be assessed by quantifying the assembled autophagosome in cytoplasm or by monitoring the fusion of autophagosome with the lysosome or vacuole. Atg8p (homologous to LC3 in mammals), localized on the autophagosomal membranes, is widely regarded as a biomarker for autophagy [22-24]. By labelling the endogenous Atg8p with an EGFP-tag on its amino-terminal, the fused EGFP-Atg8p will functionally embed into the autophagosomal membranes, and then enter the vacuole with the autophagosomes during autophagy be activated. Due to the resistance of EGFP moiety against the vacuolar proteases, the EGFP fragments (proc.EGFP) will accumulate in vacuole while the Atg8p moiety be degraded. Therefore, autophagic activity increases with increasing levels of the proc.EGFP. In this study, we labelled the endogenous Atg8p with an EGFPtag on its amino-terminal in FIM1- and T1-related engineered strains using the CRISPR/Cas9 system, and the cell lysates were prepared and analyzed by western blot with the anti-GFP antibody as described above.

\section{Spot assay}

The Brefeldin A (BFA), an antagonist against the ER to cis-Golgi trafficking, was used in spot assay for comparing the difference of this anterograde vesicular transport between the FIM1 strain and the T1 mutant. The logphase cells were harvested and adjusted to an $\mathrm{OD}_{600}$ of 0.5 , and then continuously diluted to $10^{-5}$ with $\mathrm{ddH}_{2} \mathrm{O}$. $3 \mu \mathrm{L}$ of serial dilutions of each strain was spotted onto YPD plates in the absence (vehicle) or in presence of the BFA $(10 \mu \mathrm{g} / \mathrm{mL}$, Solarbio\#B8581). Growth differences were recorded following incubation at $30^{\circ} \mathrm{C}$ for $48 \mathrm{~h}$.

\section{Statistical analysis}

All the $p$-values were calculated using an unpaired twotailed Student's $t$ test, which was considered to be significant if the value was less than 0.05 . The intensities from western blot assay was quantified using the GeneTools 4.00. Each assay was done in triplicate at least and the error bars represent the normalized standard deviation of replications.

\section{Results}

Secretory expression of the heterologous Est1E was improved by irradiation mutagenesis

To evaluate the yields of heterologous protein in $K$. marxianus, a ruminal feruloyl esterase Est1E (Genbank 
No. $M H 212232$, Additional file 1: Table S1) was elected as a biomarker and heterologously expressed in the FIM1 strain or related mutants. As shown in Fig. 1b, SDSPAGE revealed an additional Est1E brand at $27 \mathrm{kDa}$ in the fermentation supernatant of the FIM1/Est1E. The secreted Est1E exhibited hydrolytic activity on the artificial substrate CNPF with enzyme activity being only $30.46 \pm 7.35 \mathrm{U} / \mathrm{mL}$ (Fig. 1c).

This FIM1/Est1E recombinant was then used as a parental strain and $\mathrm{UV}_{-}{ }^{60} \mathrm{Co}-\gamma$ irradiation mutagenesis was carried out to improve the productivity of heterologous proteins. The expression of Est1E secreted by the mutants was calculated by quantifying its hydrolytic activity on CNPF in a high-throughput screening manner (Additional file 1: Figures S1-S3). Statistical analysis showed that the relative activity of Est1E secreted by the mutants against the wild-type followed normal distribution, and only 47 out of the 10,000 mutants showed at least 5-times higher activity of Est1E compared to the parental recombinant (Fig. 1a). Among the 47 mutants, one mutant (termed as T1/Est1E) showed at least tenfold elevated activity of Est1E $(322.5 \pm 75.08 \mathrm{U} / \mathrm{mL})$ compared to the parental FIM1/Est1E, and was thus identified and employed as a representative for later experiments (Fig. 1b, c). Additionally, under fed-batch fermentation, the Est1E secreted from this T1/Est1E mutant was accumulated in the supernatant up to $1.87 \mathrm{~g} / \mathrm{L}$ at $72 \mathrm{~h}$ (Additional file 1: Figure S4).

\section{Vesicle trafficking was enhanced while autophagy be weakened in the T1/Est1E mutant}

RNA-seq was performed to track and compare the alteration of genome-wide gene expression in the
FIM1/Est1E and the T1/Est1E recombinants (Additional file 2). Transcriptional profiling revealed that a number of genes which were engaged in vesicle trafficking or transport pathways (e.g., SEC23, SEC24, TRS20, TRS65, SFB3 and ARL3, etc.) were significantly upregulated in the T1/Est1E mutant in a time-dependent manner, concomitant with noticeable downregulation of many genes related to oxidative stress response (e.g., $H A C 1, Y A P 1$ and $S O D 1$, etc.) and autophagy (e.g., ATG3, ATG8 and PEP4, etc.), especially at $72 \mathrm{~h}$ over the course of cultivation (Fig. 2a). This inferred that the vesicle trafficking might be intensified while the autophagy might be inhibited in the T1/Est1E recombinant, which was verified in the following experiments.

In the spot assay with $10 \mu \mathrm{g} / \mathrm{mL}$ of BFA, the growth of T1/Est1E recombinant was much better than the FIM1/Est1E under $10^{-4}$ dilution (Fig. 2b), indicating that the ER to cis-Golgi trafficking was enhanced in the T1/Est1E recombinant. To verify the autophagic activity, we quantified the cumulant of the vacuolar proc. EGFP in the indicated recombinants. As shown in Fig. 2c, d, the accumulation of proc.EGFP fragments in both the FIM1/Est1E and the T1/Est1E recombinants increased with time (from 24 to $96 \mathrm{~h}$ ); in each of the four indicated time-points, the cumulant of proc.EGFP fragments in the FIM1/Est1E was virtually higher than that in the T1/Est1E recombinant (Fig. 2c) and the difference was statistically significant at $48 \mathrm{~h}$ and $72 \mathrm{~h}(p<0.01)$ (Fig. 2d). These results indicated that autophagy in the T1/Est1E recombinant was lower than that in the FIM1/Est1E, which was consistent with our transcriptional profiling observations.
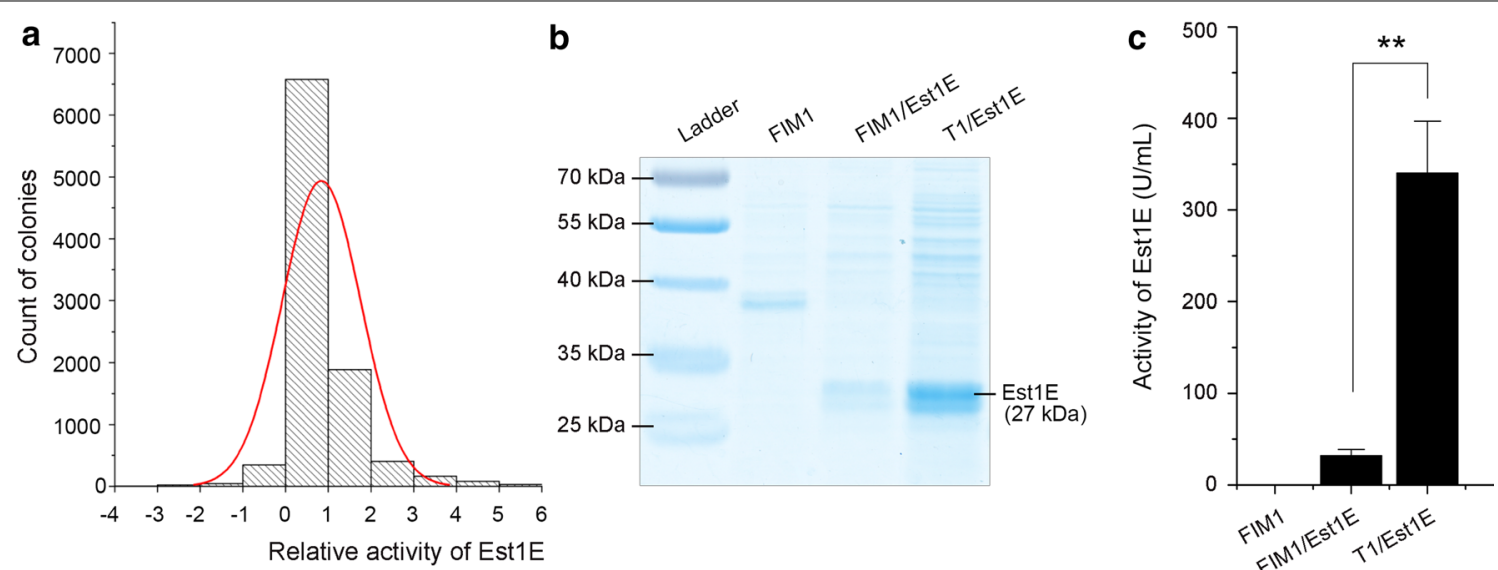

Fig. 1 Secretory expression of the heterologous Est1E in K. marxianus was improved and identified. a Distribution of the relative activity of Est1E secreted by the irradiated mutants against to the wild-type FIM1/Est1E recombinant, the red curve represented normal distribution fitting; $\mathbf{b}$ SDS-PAGE analysis for evaluating the expression of Est1 $\mathrm{E}$ in the fermentation supernatants; $\mathbf{c}$ enzymatic activity of Est $1 \mathrm{E}$ in the fermentation supernatants; bars \pm SD; ${ }^{* *} p<0.01$ vs FIM1/Est1E recombinant 


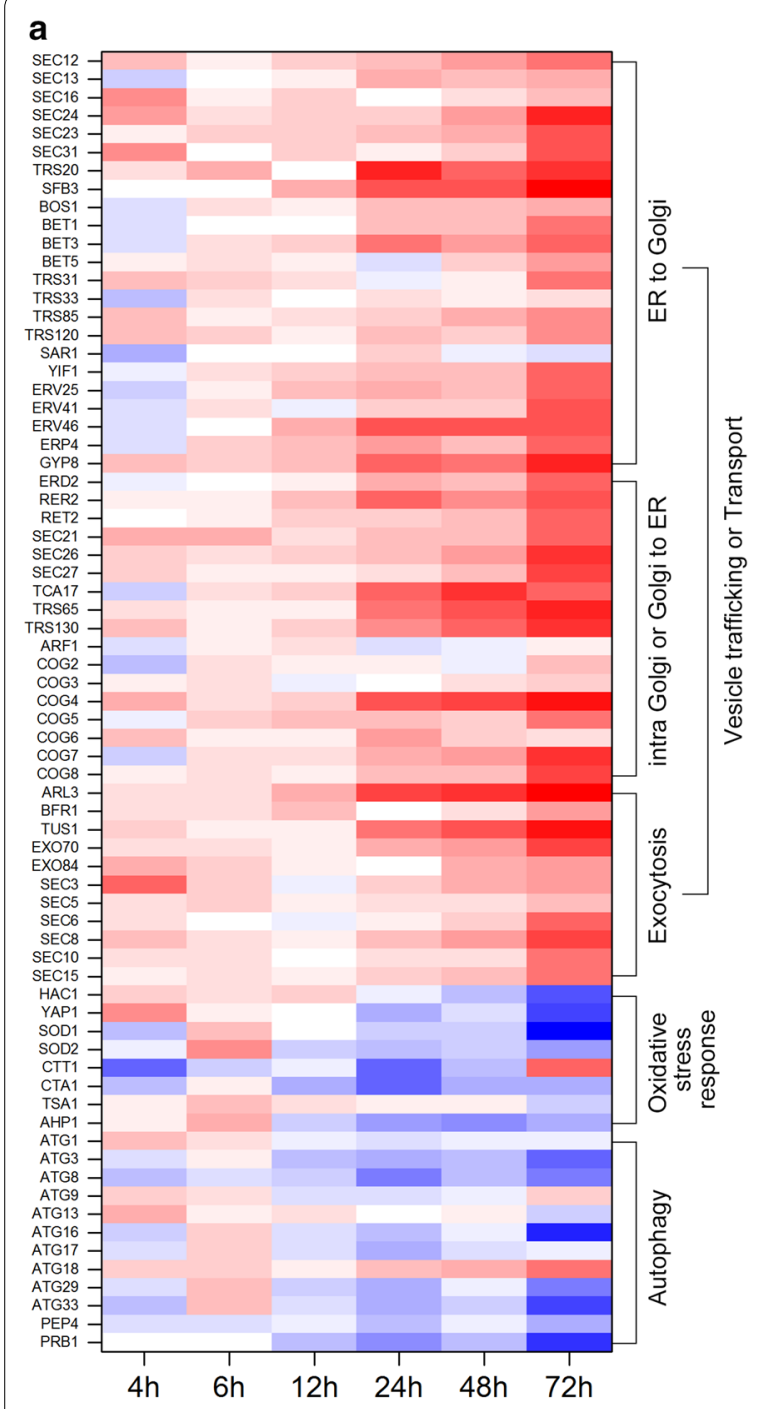

b

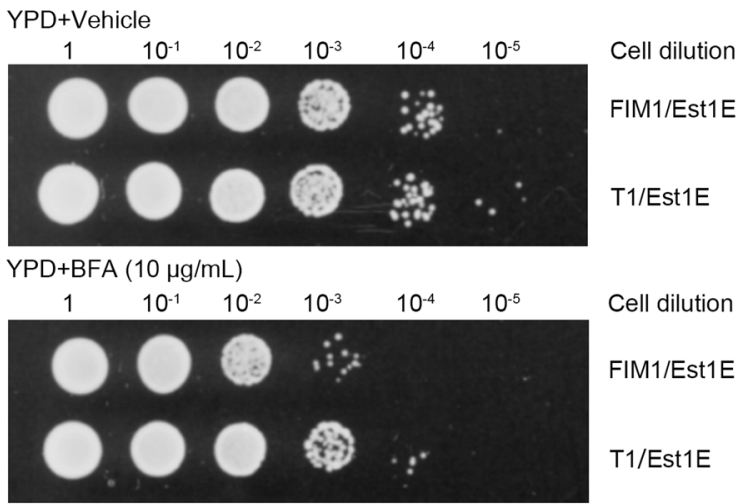

C

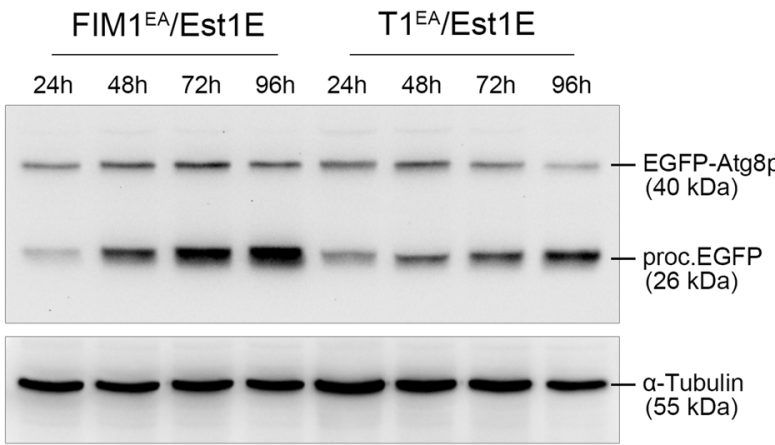

d

Relative transcriptional pattern of genes in T1 to FIM1 ( $\log _{2}$ fold change)

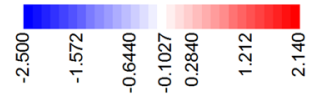

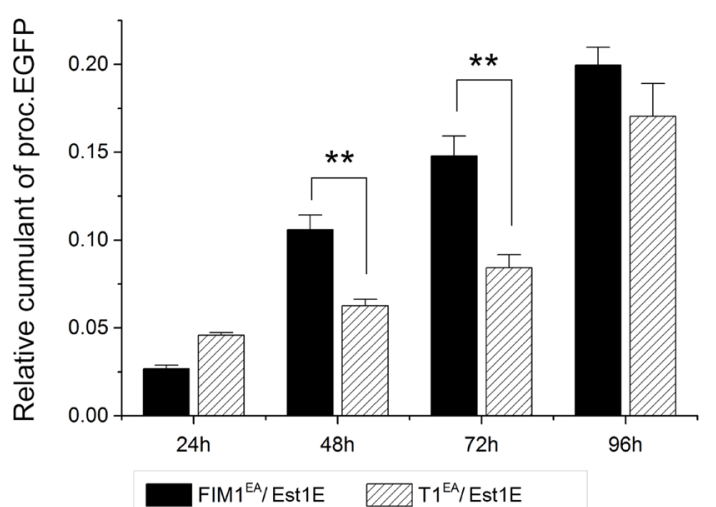

Fig. 2 Transcriptomic analysis and experimental verification. a Relative transcriptional profile of genes engaged in the intracellular vesicle trafficking, oxidative stress response and autophagy pathways; $\mathbf{b}$ proliferation and resistance of the FIM1/Est1E or the T1/Est1E recombinants against BFA treatment; $\mathbf{c}$ Western blot analysis to monitor the cumulant of the vacuolar proc.EGFP fragments, a-tubulin was designed as internal standard; $\mathbf{d}$ quantitatively analysis for relative cumulant of the proc.EGFP fragments according to its gray intensity of bands showed in c, the cumulant of proc. EGFP fragments was normalized with the intensity of its respective a-tubulin; bars \pm SD; ${ }^{* *} p<0.01$ vs FIM1/Est1E recombinant

Mtc6p, a hypothetical ER protein, played a key role in secretory expressing Est1E in K. marxianus

Whole genome sequencing were performed to find out the key genes that might be responsible for the different expression of Est1E between the FIM1/Est1E and the T1/ Est1E recombinants. Compared to the FIM1/Est1E, 67
SNPs and 5 indels were found throughout the genome of the T1/Est1E mutant, which led to 31 non-synonymous mutations (Additional file 1: Table S3). Eukaryotic orthologous groups (KOG) analysis showed that $10.2 \%$ of the non-synonymous mutant genes were predicted to participate in intracellular trafficking or vesicular transport, 
$8.47 \%$ in regulating cellular cytoskeletal events, and $6.78 \%$ in regulating translation or ribosomal biogenesis pathways (Fig. 3).

Considering that the productivity of heterologous Est1E was increased remarkably along with the intracellular vesicle trafficking be enhanced in the T1/Est1E

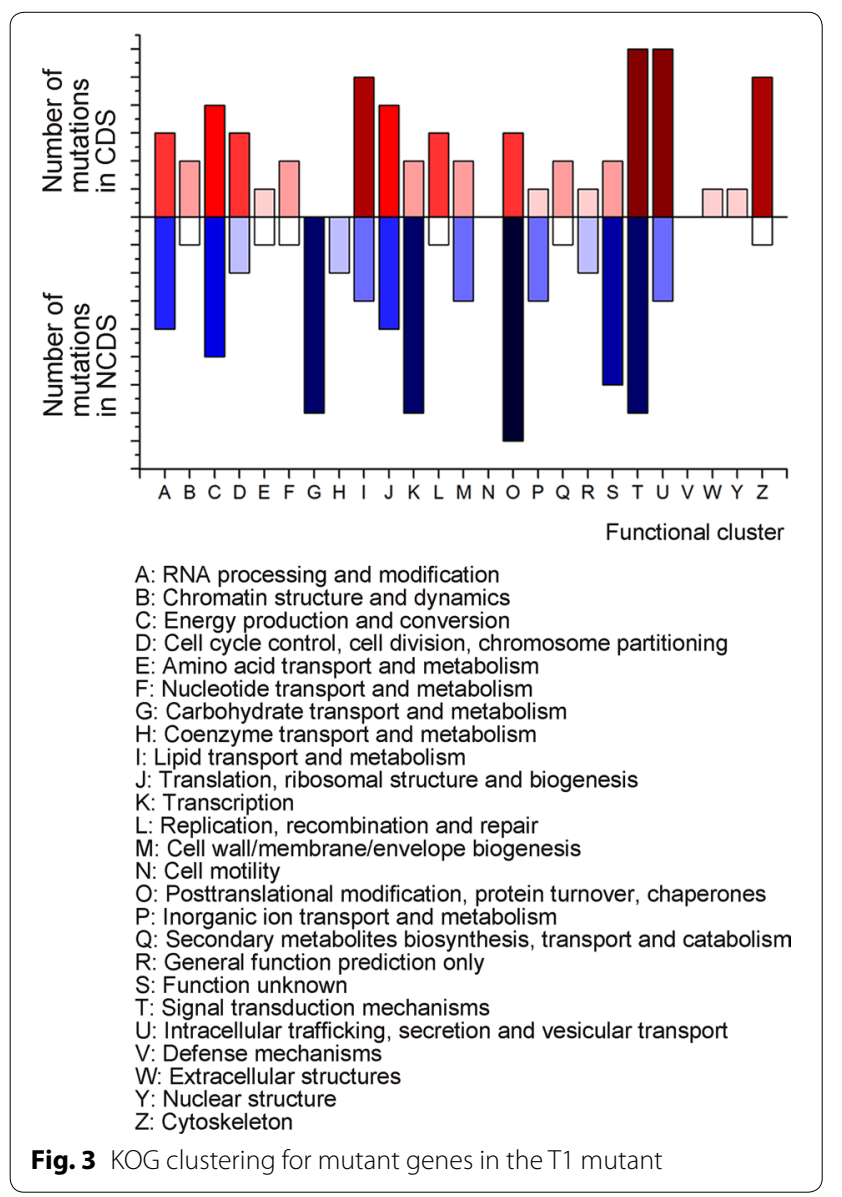

mutant, we only focused on the mutant genes which be predicted to play a role in the amino-acid metabolism (IDP1, PYC2 and HER2), the protein biosynthesis (CMS1, $M D N 1, R P F 1$ and KRI1) and the vesicle transport pathways (HRD3, YNR021W, MTC6, TWF1, CAD2, ERF4, $S E A 3, S S K 1, D R S 2$ and VPS10). Exclusive of the essential genes, 10 of the interested genes were regarded as candidates and be examined their impact on the productivity of heterologous proteins in $K$. marxianus (Table 2). Gene editing, such as deletion or splicing mutation were accomplished using the CRISPR/Cas9 system (Additional file 1: Figure S5). Unlike other 9 mutations in which we deleted the whole ORF, we only deleted a nucleotide fragment from 721 to 903 of MTC6 (covering the specific SNP at C755 $\Delta$ ) in FIM1 (FIM1 $m t c 6^{721-903 \Delta}$ ) to disrupt the Mtc6p (coded by MTC6) with minimized impact on its adjacent gene, because there was an overlapping region (30 bp) of the $5^{\prime}$-end of MTC6 with the $5^{\prime}$-end of its adjacent gene, complete deleting the ORF of MTC6 might have an impact on the expression of this adjacent gene. As shown in Fig. 4, the deletion or splicing of any of the 10 candidates in the FIM1 strain improved the secretory expression of heterologous Est1E (Table 3). Especially, splicing MTC6 in FIM1 (FIM1 $m t c 6^{721-903 \Delta}$, Est1E) resulted in 7.27-fold higher activity of Est1E than that of the FIM1/Est1E (Fig. 4a). Compared to the T1/ Est1E which harbored all 31 non-synonymous mutations, splicing MTC6 contributed $19.22 \%$ to the expression of Est1E, while deleting SEA3 or YNRO21W only contributed $6.21 \%$ or $5.93 \%$, respectively. Notably, double mutation of $m t c 6^{721-903 \Delta}$ and sea $3 \Delta$ contributed $45.08 \%$ to the expression of Est1E, and triple mutation of $m t c 6^{721-903 \Delta}$, sea3 $\Delta$ and $y n r 021 w \Delta$ contributed as much as $53.26 \%$ (Fig. 4a, Table 3).

In addition, we also examined the impact of $m t c 6^{721-903 \Delta}$, sea3s and/or $y n r 021 w \Delta$ mutations on

Table 2 Non-synonymous mutations in the T1 mutant which be involved in amino-acid metabolism, protein biosynthesizing or intracellular trafficking

\begin{tabular}{llll}
\hline Genes & Mutations on ORF & Variations & Functional annotation \\
\hline CMS1 & A161C & Asp54 to Ala & Putative subunit of the 90S preribosome processome complex \\
IDP1 & G1087A & Mitochondrial NADP-specific isocitrate dehydrogenase \\
CDA2 & T391A & Cys131 to Ser & Chitin deacetylase, be involved in cell wall organization \\
HRD3 & G526A & Ala176 to Thr & ER membrane protein that plays a central role in ERAD \\
YNR021W & 1211+C & Frameshift mutation & ER membrane protein \\
MTC6 & C755D & Frameshift mutation, Leu256* & Hypothetical ER and vacuolar protein \\
SSK1 & A1505C & Asp502 to Ala & Cytoplasmic phosphorelay intermediate osmosensor and regulator \\
ERF4 & A789T & Gln262 to His & Palmitoyltransferase subunit \\
SEA3 & A1814T & His605 to Leu & Subunit of SEACAT \\
TWF1 & A811G & lle271 to Val & Highly conserved actin monomer-sequestering protein \\
\hline Stop codon & &
\end{tabular}

* Stop codon 


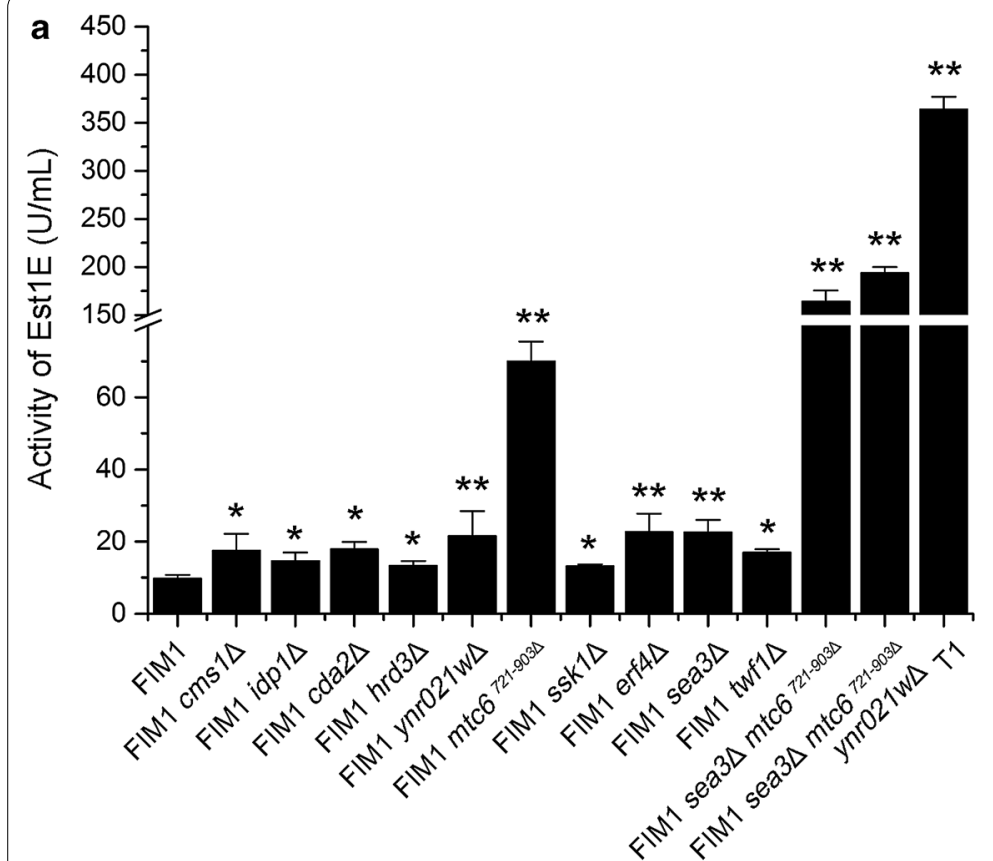

Est1E-expressing recombinants

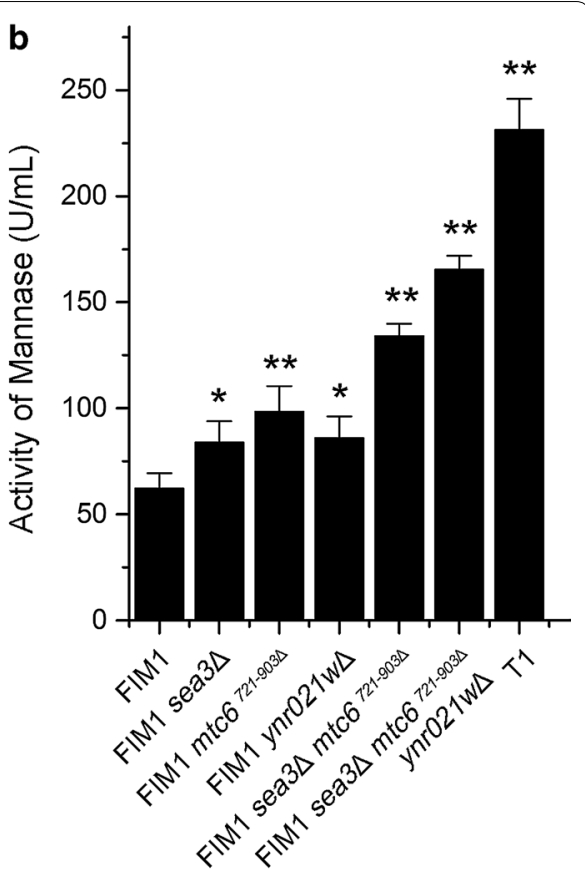

Man330-expressing recombinants

Fig. 4 Influences induced by the candidate mutations on secretory expressing the heterologous proteins in K. marxianus. a Enzymatic activity of Est1E secreted from the indicated mutational Est1E-expressing recombinants; $\mathbf{b}$ enzymatic activity of mannase secreted from the indicated mutational Man330-expressing recombinants; bars \pm SD; ${ }^{*} p<0.05$ or ${ }^{* *} p<0.01$ vs FIM1 recombinant

Table 3 Effect of non-synonymous mutations on the expression of heterologous proteins

\begin{tabular}{|c|c|c|c|c|}
\hline Strains & Activity of Est $1 \mathrm{E}(\mathrm{U} / \mathrm{mL})$ & $\begin{array}{l}\text { Percentage of Est1E expression } \\
\text { in FIM1 mutant over Est1E } \\
\text { expression in } \mathrm{T} 1(\%)\end{array}$ & $\begin{array}{l}\text { Activity } \\
\text { of Man330 (U/ } \\
\mathrm{mL})\end{array}$ & $\begin{array}{l}\text { Percentage of Man } 330 \\
\text { expression in FIM1 mutant } \\
\text { over Man330 expression in T1 } \\
\text { (\%) }\end{array}$ \\
\hline $\mathrm{T} 1$ & $363.91 \pm 12.99$ & 100 & $231.29 \pm 14.64$ & 100 \\
\hline FIM1 sea3 $\Delta$ mtc $^{721-903 \Delta}$ ynr021w $\Delta$ & $193.81 \pm 6.09$ & 53.26 & $165.39 \pm 6.47$ & 71.5 \\
\hline FIM1 sea3 $\Delta m t c 6^{721-903 \Delta}$ & $164.05 \pm 11.45$ & 45.08 & $134.07 \pm 5.79$ & 57.97 \\
\hline FIM1 mtc $6^{721-903 \Delta}$ & $69.95 \pm 5.51$ & 19.22 & $98.52 \pm 11.86$ & 42.6 \\
\hline FIM1 sea3 $\triangle$ & $22.61 \pm 3.39$ & 6.21 & $83.91 \pm 9.97$ & 36.28 \\
\hline FIM1 ynr021w & $21.57 \pm 6.91$ & 5.93 & $86.05 \pm 10.07$ & 37.2 \\
\hline FIM1 erf4 $\triangle$ & $22.71 \pm 5.03$ & 6.24 & Non-detected & - \\
\hline FIM1 cda2 $\triangle$ & $17.91 \pm 1.98$ & 4.92 & Non-detected & - \\
\hline FIM1 twf1 $\triangle$ & $16.98 \pm 0.93$ & 4.67 & Non-detected & - \\
\hline FIM1 $\mathrm{cms} 1 \triangle$ & $17.53 \pm 4.63$ & 4.82 & Non-detected & - \\
\hline FIM1 idp $1 \triangle$ & $14.63 \pm 2.38$ & 4.02 & Non-detected & - \\
\hline FIM1 hrd3 $\triangle$ & $13.35 \pm 1.24$ & 3.67 & Non-detected & - \\
\hline FIM1 ssk1 & $13.24 \pm 0.47$ & 3.64 & Non-detected & - \\
\hline
\end{tabular}

expressing another heterologous protein in $K$. marxianus, mannase Man330. Compared to T1/Man330, splicing MTC6 contributed $42.6 \%$ to the expression of Man330, while deletion of SEA3 or YNRO21W contributed $36.28 \%$ or $37.2 \%$, respectively. Furthermore, triple mutation of $m t c 6^{721-903 \Delta}$, sea3 $\Delta$ and $y n r 021 w \Delta$ contributed as much as $71.5 \%$ to the expression of Man330 (Fig. 4b, Table 3). These results indicated that $m t c 6^{721-903 \Delta}$, missing the 721-903th nucleotides fragment which covered the SNP at C755, played a key role 
in the secretory expression of heterologous proteins in K. marxianus.

\section{Premature termination of Mtc6p resulted in increased productivity of Est1E in K. marxianus}

Alignment analysis revealed a cytosine deletion on the 755 loci at the ORF of MTC6 in the T1 mutant, which would otherwise lead to frameshift mutation and translate into a premature polypeptide of 255 amino-acid residues (missing 336 amino-acids on its carboxyl terminus) (Fig. 5a). To verify whether the single-base deletion at C755 in MTC6 brought the positive influence on expressing the desired proteins, we reinstated the cytosine deletion at 755 loci of MTC6 in the T1 mutant via CRISPR/Cas9 system and obtained the T1 MTC6 mutant (Fig. 5a). As shown in Fig. 5b, the productivity of Est1E in the T1 MTC6/Est1E recombinant was only $130.28 \pm 7.34 \mathrm{U} / \mathrm{mL}$, as compared to $383.93 \pm 94.04 \mathrm{U} / \mathrm{mL}$ in the $\mathrm{T} 1 /$ Est1E, suggesting that this single-base deletion at C755 of MTC6 might be responsible for the apparent increase in the yields of desired proteins expressed in $K$. marxianus.

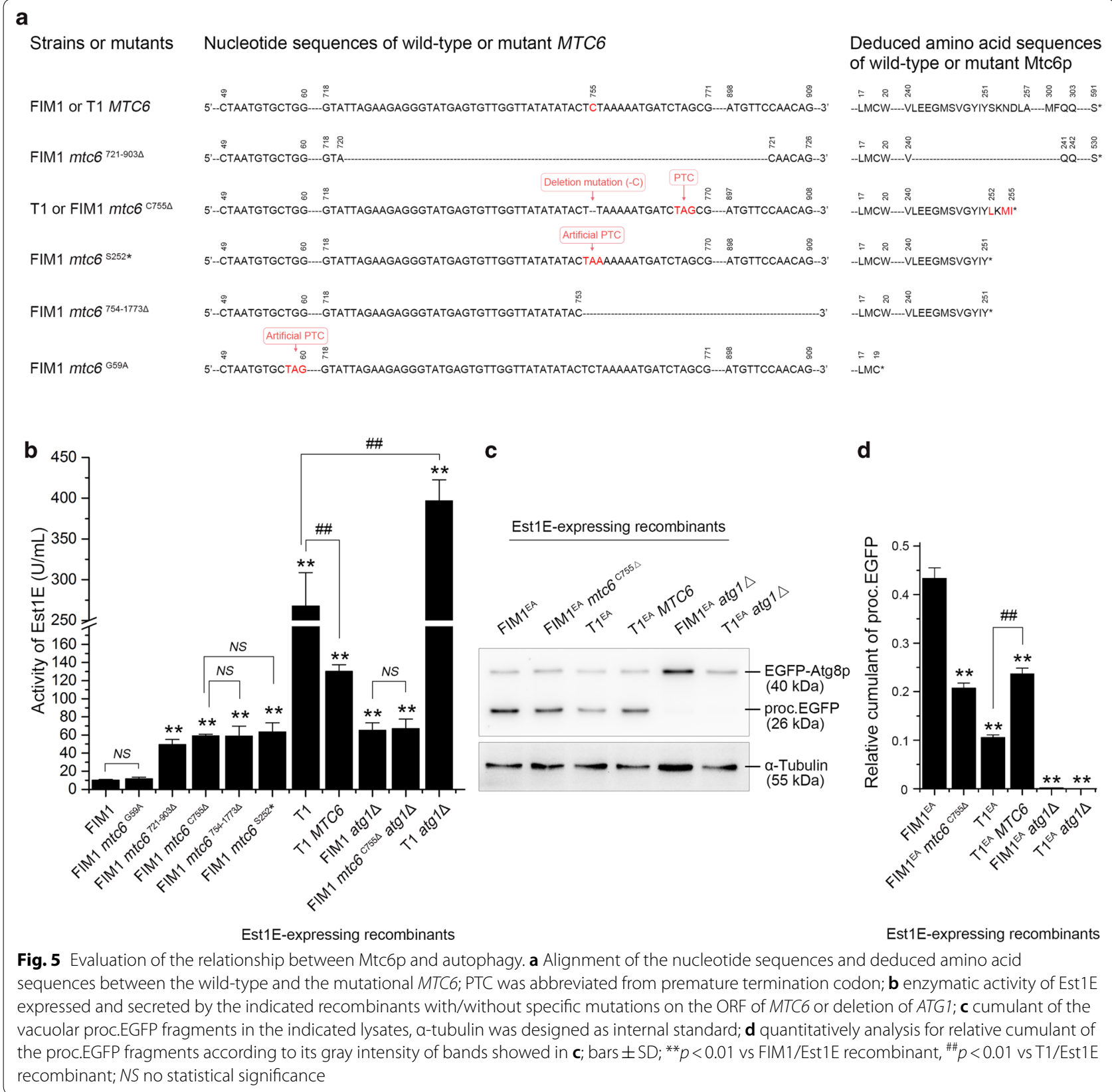


(See figure on next page.)

Fig. 6 Influences of attenuated or interdicted autophagy on secretory expression of the heterologous proteins in K. marxianus. a Enzymatic activity and expression of the mannase Man330 in the indicated fermentation supernatants; $\mathbf{b}$ enzymatic activity and expression of the $\beta$-1,4-endoxylanase XynCDBFV in the indicated fermentation supernatants; $\mathbf{c}$ fluorescence intensity and expression of EGFP in the indicated fermentation supernatants; bars $\pm S D ;{ }^{*} p<0.05$ or ${ }^{* *} p<0.01$ vs the FIM1 recombinant, ${ }^{\# \#} p<0.01$ vs the T1 recombinant

Furthermore, four versions of MTC6 were constructed in the FIM1 strain using CRISPR/Cas9 system (Fig. 5a, Additional file 1: Figure S5 and Table S1). As shown in Fig. $5 \mathrm{a}$, the FIM1 $m t c 6^{\mathrm{C} 755 \Delta}$ mutant was constructed by deleting a single cytosine at 755 loci of MTC6 in FIM1 to mimic the aberrant Mtc6p as observed in the T1 mutant, in which frameshift started after Tyr251 and terminated at Ile255 of polypeptide; the FIM1 $m t c 6^{\text {S252* }}$ mutant, in which the Ser252 of Mtc6p was substituted into an artificial stop codon and be early terminated at Tyr251; as well as the FIM1 $m t c 6^{754-1773 \Delta}$ mutant, which suffered nucleotide deficiency from 754 to 1773 in the ORF of MTC6 and engendered the same premature polypeptide of 251 amino-acids as the FIM1 $m$ tc $6^{\mathrm{S} 252 *}$ mutant. These three mutants shared the same sequence of amino-acids from the Met1 to Tyr251, which was identical to the aberrant Mtc6p in T1 mutant. Enzymatic assay indicated that the yields of heterologous Est1E expressed in each of these three mutants were at least 4.86-times higher than that in the FIM1/Est1E recombinant, although no statistical differences be existed between these three recombinants (Fig. 5b). In addition, given that the ORF of MTC6 overlapped with its adjacent gene, we constructed a FIM1 $m t c 6^{\mathrm{G} 59 \mathrm{~A}}$ mutant by substituting the Trp20 of Mtc6p into a stop codon, which would generate a negligible oligopeptide with only 19 amino-acids and be employed to mimic the complete deficiency of Mtc6p (Fig. 5a). However, the productivity of Est1E in the FIM1 $m t c 6^{\mathrm{G} 59 \mathrm{~A}}$ / Est1E recombinant was not significantly higher than that in the FIM1/Est1E (Fig. 5b). These suggested that the premature termination of Mtc6p, be induced by the singlebase deletion at C755 in ORF, enabled the recombinant to efficiently express and secrete the heterologous proteins in K. marxianus.

\section{Premature termination of Mtc $6 \mathrm{p}$ resulted in attenuated autophagy in $K$. marxianus}

Since the results from Fig. 2c showed that autophagy was inhibited in the T1/Est1E recombinant while displayed increased productivity of Est1E, we investigated whether the Mtc6p was involved in autophagy. As shown in Fig. $5 c$, d, the cells failed to process and produce proc. EGFP fragment when its endogenous ATG1 be deleted, indicating that the cellular autophagy should be complete interdicted by deleting ATG1 in $K$. marxianus, and these $\operatorname{atg} 1 \Delta$ mutants could be regarded as a control.
Compared to FIM1 ${ }^{\text {EA }}$ which harbored the wild-type Mtc6p, the cumulant of proc.EGFP fragment was significantly decreased in the FIM1 ${ }^{\mathrm{EA}} m t c 6^{\mathrm{C} 755 \Delta}$; whereas the accumulation of proc.EGFP fragment was dramatically increased in the T1 ${ }^{\mathrm{EA}}$ MTC6 mutant with reinstated Mtc6p, as compared to the $\mathrm{T} 1^{\mathrm{EA}}$ mutant with an intrinsic premature Mtc6p $\left(m t c 6^{\mathrm{C} 755 \Delta}\right)$ (Fig. 5c, d). These results indicated that the single-base deletion of C755 in MTC6 leaded to incomplete interdiction of autophagy, suggesting that Mtc6p might be involved in regulating autophagy in $K$. marxianus.

We then examined the productivity of Est1E in the $\operatorname{atg} 1 \Delta$ mutant, in which autophagy was interdicted. As shown in Fig. 5b, compared to FIM1/Est1E, the expression of Est1E was dramatically increased in the FIM1 $\operatorname{atg} 1 \Delta /$ Est1E recombinant; and the expression of Est1E in the FIM1 $m t c 6^{\mathrm{C} 755 \Delta} \operatorname{atg} 1 \Delta / \mathrm{Est1E}$ recombinant was slightly higher than that in the FIM1 $m t c 6^{\mathrm{C} 755 \Delta} / \mathrm{Est} 1 \mathrm{E}$, albeit no significant difference of the productivity of Est1E existed between the FIM1 $\operatorname{atg} 1 \Delta /$ Est1E and the FIM1 $m t c 6^{\mathrm{C} 755 \Delta}$ atg1 $1 /$ Est1E recombinants. Moreover, compared to $\mathrm{T} 1 / \mathrm{Est} 1 \mathrm{E}$, the productivity of Est1E substantially increased in the $\mathrm{T} 1 \mathrm{atg} 1 \Delta /$ Est1E recombinant. These results suggested that attenuating autophagy would improve the yields of desired proteins expressed in K. marxianus.

\section{Yields of various heterologous proteins could be improved by attenuating autophagy}

Extensively, in order to evaluate the impact of attenuated autophagy on expressing the desired proteins in K. marxianus, other heterologous proteins, such as the mannase Man330 ( 37 kDa), the $\beta$-1,4-endoxylanase XynCDBFV $(\sim 26 \mathrm{kDa}$, glycosylated) or the conventional EGFP $(\sim 26 \mathrm{kDa})$, was respectively expressed in the FIM1 strain or the indicated mutant which harbored mutational Mtc6p (i.e., the FIM1 $m t c 6^{\mathrm{C} 755 \Delta}$ and T1) or deficient Atg1p (i.e., the FIM1 atg1 $\Delta$ and T1 atg1 $\Delta$ ). As shown in Fig. 6, the secretory expression of all these three proteins was significantly increased in the recombinants with $m t c 6^{\mathrm{C} 755 \Delta}$ (i.e., FIM1 $m t c 6^{\mathrm{C} 755 \Delta}$ and T1) or atg1 $\Delta$ than that in the recombinants with wild-type MTC6 (i.e., FIM1 and T1 MTC6). Parallel to enzymatic activity or autofluorescence analyses, SDS-PAGE analysis confirmed observable enhancement in secretory expression of these desired proteins in context (Fig. 6). These observations 
a

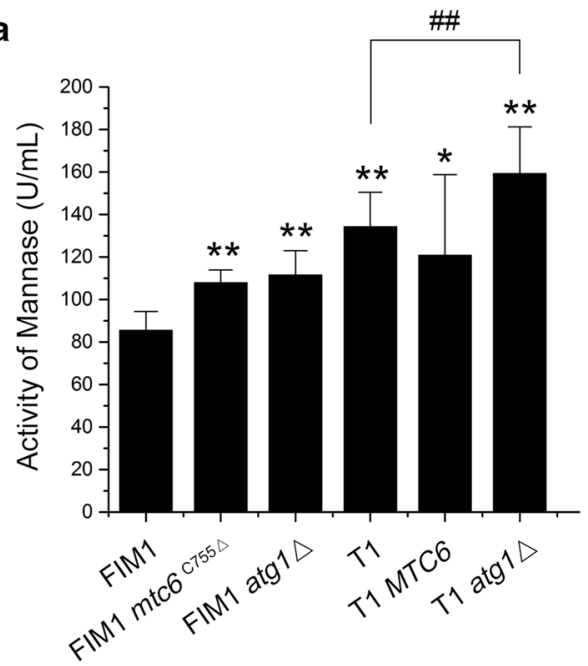

Man330-expressing recombinants

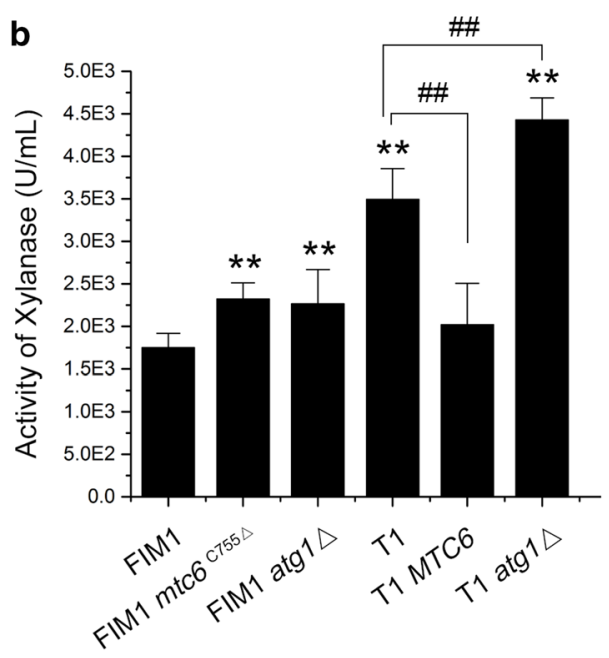

XynCDBFV-expressing recombinants

C

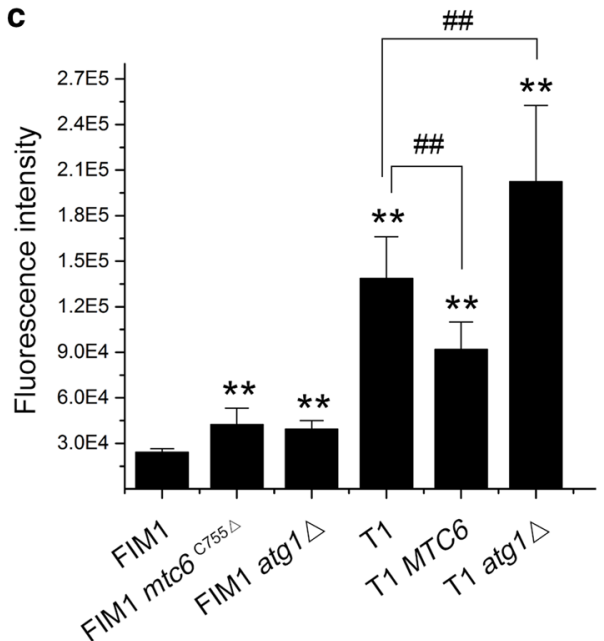

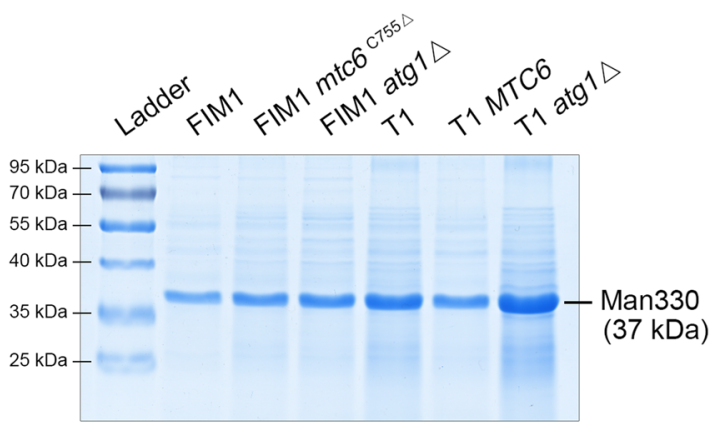
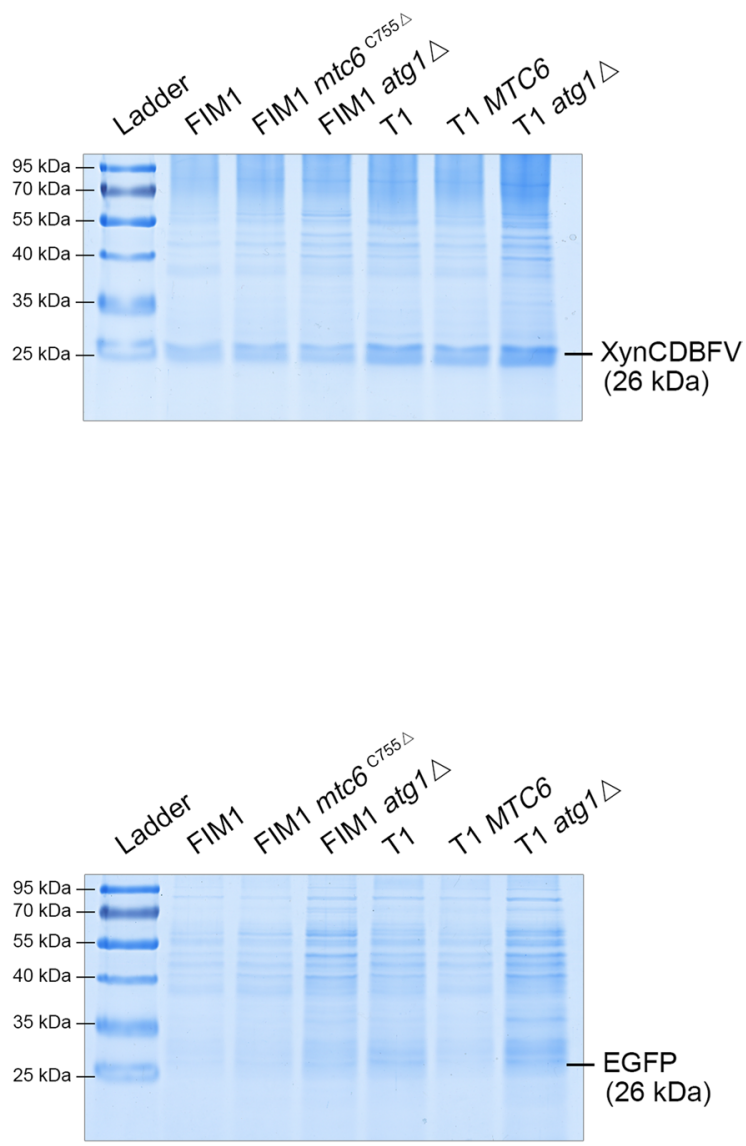
indicated that the yields of various heterologous proteins expressed in K. marxianus could be improved by inhibiting or interdicting autophagy, and the Mtc6p might be designed as a potential target for modulating the native autophagy.

\section{Discussion}

In this work, we identified one $K$. marxianus mutant (termed T1) with the ability to efficiently express and secrete various desired proteins, whatever the heterologous ruminal feruloyl esterase Est1E, the mannase Man330, the $\beta$-1,4-endoxylanase XynCDBFV or the EGFP. The T1/Est1E recombinant yielded $1.87 \mathrm{~g} / \mathrm{L}$ of Est1E in supernatant under fed-batch fermentation for $72 \mathrm{~h}$, to our knowledge, it was so far the highest reported yields of heterologous protein produced by $K$. marxianus. It meant that this $\mathrm{T} 1$ mutant held the potential to be designed as chassis and be used in the fundamental experiments or the industrial applications.

Compared to the parental FIM1/Est1E recombinant, the vesicle trafficking was enhanced while autophagy be weakened in the T1/Est1E mutant. It might be explained by the fact that the upregulated Trs65p (Fig. 2a), a subunit of the TRAPPII complex which participates in an Arf1p-GEF effector loop [25], would facilitate TRAPPII to interact with Arf1p and boost COPI-mediated vesicle trafficking, in turn enable the T1 mutant to withstand BFA cytotoxicity (Fig. 2b). Besides, the intensive COPIvesicles would effectively retrieve the escaped luminal proteins or components which be required for anterograde transport, this benefits the COPII-vesicles assembling and would facilitate the vesicles to carry cargoes from ER to cis-Golgi [26]. The intensive circuit between the ER and the Golgi apparatus would not only stabilize the ER-Golgi interface, but also lighten the ER-stress, and then inactivate the unfolded protein response (UPR) and the ER-associated degradation (ERAD) pathway [27]. In this case, the feedback inhibition induced by UPR on transcriptional activity of the target genes would be repealed, and more precursor proteins would escape being degraded from the ERAD pathway.

Moreover, we identified and reported a novel functional protein Mtc6p, that was the premature Mtc6p, which was induced by single-base deletion at C755 in its ORF and be early terminated at Tyr251 of polypeptide, dramatically improved the secretory expression of desired proteins, accompanying with attenuated autophagy. And the yields of desired proteins was further improved by interdicting autophagy, although no more improvement be detected in the double mutant with truncated Mtc6p and deficient Atg1p (FIM1 $m t c 6^{\mathrm{C} 755 \Delta}$ atg $1 \Delta$ ) as compared to the FIM1 atg1 $\Delta$ mutant (Figs. 2, 5). This inferred that the Mtc6p might be a downstream target of Atg1p and be involved in regulating autophagy in $K$. marxianus. Intriguingly, complete lack of Mtc6p in FIM1 (FIM1 $m t c 6^{\mathrm{G} 59 \mathrm{~A}}$ ) failed to elevate the productivity of Est1E in $K$. marxianus, while only the carboxyl-terminal truncated Mtc6p did (i.e., the FIM1 $m t c 6^{\mathrm{C} 755 \Delta}$, FIM1 $m t c 6^{\text {S252* }}$ and FIM1 $\left.m t c 6^{754-1773 \Delta}\right)$. It could be supposed as the negative dominant effect, in which the carboxyl-terminal truncated Mtc6p might inhibit the function of other molecules by adversely interacting. However, the specific molecular mechanism and their spatiotemporal interaction required for further exploration.

So far as we know, it was the first report that autophagy brought negative influence on biosynthesizing the desired proteins in the engineered yeasts, especially in K. marxianus. Previous studies revealed that the secretory and autophagy pathways are intimately linked and shared many machineries, although they are generally thought of as a biosynthetic or a degradative branch of the endomembrane system [16, 28]. For instance, Atg1p not only phosphorylates Atg9p for organizing the autophagosome, but also phosphorylates the Sec23Ap at Ser207 and Thr405 residues, which otherwise reduce the interaction between Sec23Ap and Sec31Ap, eventually suppress the secretion routes $[29,30]$. The ERES provides biomembranes or some essential components for assembling the autophagosome through COPII-coated vesicles, which could assist the phagophore in building or maturation into an autophagosome [16, 28]. All these evidence implied a tradeoff existed between the autophagy and vesicular secretion, which led to both the pathways to contend for constituent or functional elements. As we demonstrated in this manuscript, repressing the cellular autophagy improved the yields of various heterologous proteins in $K$. marxianus, it might be explained that the essential resources were reallocated from the attenuated autophagy to the secretory pathway, what intensified its vesicle trafficking and then improved the secretory expression of the desired proteins (Figs. 2, 5).

Based on these findings, we raised a prospect that whether the yields of desired proteins will be higher if the engineered yeast be modified by attenuating autophagy coupled with the existing strategies, and much more efforts are undergoing to optimize these microbial cell factories for biosynthesizing the desired proteins.

\section{Conclusions}

This was the first study to report that the Mtc6p be involved in regulating autophagy in $K$. marxianus, and that inhibited or interdicted autophagy could lead to a substantial increase in the yields of desired proteins in K. marxianus. In view of this, the Mtc6p could regarded as a potential target for modulating autophagy, although 
further studies are warranted to investigate the molecular mechanisms of Mtc6p in regulating autophagy.

\section{Additional files}

Additional file 1: Figure S1. Strategies for screening desirable mutants in a high-throughput manner. Figure $\mathbf{S 2}$. A linear relationship was existed between the activity of Est $1 E$ and the enzyme concentration. Figure S3. Identification of the mutants with excellent ability in expressing the heterologous Est1E. Figure S4. Purification and quantification of the Est1E expressed and secreted by the T1/Est1E recombinant. Figure S5. Establishment of the specific mutants using CRISPR/Cas9 system. Table S1. Amino-acid sequences of the Est1E and the full or truncated Mtc6p. Table S2. Primers and DNA sequences used in this study. Table S3. Information of the specific SNP or indel in the genome of T1 mutant.

Additional file 2. Detail information of the transcriptional analysis.

\section{Abbreviations}

BFA: Brefeldin A; CNPF: 2-chloro-4-nitropheyl ferulate; EGFP: enhanced green fluorescent protein; ER: endoplasmic reticulum; ERES: endoplasmic reticulum exit sites; ERAD: ER-associated degradation; GOX: glucose oxidase; indel: insertion or deletion of oligonucleotide fragments; KOG: eukaryotic orthologous groups; ORF: open reading frame; PTC: premature termination codon; SNP: single nucleotide polymorphisms; SOD: superoxide dismutase; UPR: unfolded protein response.

\section{Authors' contributions}

Conceptualization, HL, YL, YY; methodology, YL, JGZ, TFS. MZW; formal analysis, YL, WJM; writing —original draft, YL; writing—review and editing, HL, YL, WSY; visualization, HL, YL, MZW; funding acquisition, HL. All authors read and approved the final manuscript.

\section{Author details}

1 State Key Laboratory of Genetic Engineering, School of Life Science, Fudan University, Shanghai 200438, People's Republic of China. ${ }^{2}$ Shanghai Engineering Research Center of Industrial Microorganisms, Shanghai 200438, People's Republic of China. ${ }^{3}$ NUS Synthetic Biology for Clinical and Technological Innovation, 28 Medical Drive, Singapore 117456, Singapore. ${ }^{4}$ Department of Biochemistry, Yong Loo Lin School of Medicine, National University of Singapore, 8 Medical Drive, Singapore 117597, Singapore.

\section{Acknowledgements}

Thanks to Prof. Bo-Zhong Mu at East China University of Science and Technology for technical assistance; Mo-Zhu Ding for her linguistic assistance during the preparation of this manuscript; and thanks to our laboratory colleagues and research staff members for their constructive advice and help.

\section{Competing interests}

The authors declare that they have no competing interests.

\section{Availability of data and materials}

We provide all necessary data for the publication of this article. All additional data is present in the article and the additional material documents.

\section{Consent for publication}

We hereby give the Journal of Microbial Cell Factories the right and permission to publish this article.

\section{Ethics approval and consent to participate}

Not applicable.

\section{Funding}

This work was supported by the National High Technology Research and Development Program of China [Grant Numbers 2013AA102803, 2014AA021301], the National Natural Science Foundation of China [Grant Numbers 31770094, 91731310 and 31771384], the Science and Technology
Research Program of Shanghai [Grant Number 18391901800] and the Open Research Funds of the State Key Laboratory of Genetic Engineering, Fudan University.

\section{Publisher's Note}

Springer Nature remains neutral with regard to jurisdictional claims in published maps and institutional affiliations.

Received: 8 June 2018 Accepted: 8 September 2018

Published online: 14 September 2018

\section{References}

1. Rocha SN, Abrah O-Neto J, Cerdán ME, González-Siso MI, Gombert MI. Heterologous expression of glucose oxidase in the yeast Kluyveromyces marxianus. Microb Cell Fact. 2010;9(1):4.

2. Raimondi S, Uccelletti D, Amaretti A, Leonardi A, Palleschi C, Rossi M. Secretion of Kluyveromyces lactis Cu/Zn SOD: strategies for enhanced production. Appl Microbiol Biotechnol. 2010;86(3):871-8.

3. Soares Braganca CR, Colombo LT, Roberti AS, Tocantins Alvim MC, Cardoso SA, Portes Reis KC, de Paula SO, Da Silveira WB, Lopes Passos FM. Construction of recombinant Kluyveromyces marxianus UFV-3 to express dengue virus type 1 nonstructural protein 1 (NS1). Appl Microbiol Biotechnol. 2015;99(3):1191-203.

4. Gombert AK Jr, Madeira JV, Cerdan M, Gonzalez-Siso M. Kluyveromyces marxianus as a host for heterologous protein synthesis. Appl Microbiol Biotechnol. 2016;100(14):6193-208.

5. Galinari E, Almeida-Lima J, Macedo GR, Mantovani HC, Rocha HAO. Antioxidant, antiproliferative, and immunostimulatory effects of cell wall alpha-D-mannan fractions from Kluyveromyces marxianus. Int J Biol Macromol. 2018;109:837-46.

6. Wu W, Hung W, Lo K, Chen Y, Wan H, Cheng K. Bioethanol production from taro waste using thermo-tolerant yeast Kluyveromyces marxianus K21. Bioresour Technol. 2016;201:27-32.

7. Delic M, Valli M, Graf AB, Pfeffer M, Mattanovich D, Gasser B. The secretory pathway: exploring yeast diversity. FEMS Microbiol Rev. 2013;37(6):872-914.

8. Aw R, Polizzi KM. Can too many copies spoil the broth? Microb Cell Fact. 2013:12:128.

9. Kim H, Yoo SJ, Kang HA. Yeast synthetic biology for the production of recombinant therapeutic proteins. FEMS Yeast Res. 2014;15(1):1-16.

10. Tang H, Bao X, Shen Y, Song M, Wang S, Wang C, Hou J. Engineering protein folding and translocation improves heterologous protein secretion in Saccharomyces cerevisiae. Biotechnol Bioeng. 2015;112(9):1872-82.

11. Van Zyl JHD, Den Haan R, Van Zyl WH. Overexpression of native Saccharomyces cerevisiae ER-to-Golgi SNARE genes increased heterologous cellulase secretion. Appl Microbiol Biotechnol. 2016;100(1):505-18.

12. Sanchez-Wandelmer J, Ktistakis NT, Reggiori F. ERES: sites for autophagosome biogenesis and maturation? J Cell Sci. 2015;128(2):185-92.

13. Karanasios E, Walker SA, Okkenhaug H, Manifava M, Hummel E, Zimmermann H, Ahmed Q, Domart M, Collinson L, Ktistakis NT. Autophagy initiation by ULK complex assembly on ER tubulovesicular regions marked by ATG9 vesicles. Nat Commun. 2016;7(12420):12420.

14. Gan W, Zhang C, Siu KY, Satoh A, Tanner JA, Yu S. ULK1 phosphorylates Sec23A and mediates autophagy-induced inhibition of ER-to-Golgi traffic. BMC Cell Biol. 2017;18(1):22.

15. Joo JH, Wang B, Frankel E, Ge L, Xu L, lyengar R, Li-Harms X, Wright C, Shaw TI, Lindsten T, et al. The noncanonical role of ULK/ATG1 in ER-to-Golgi trafficking is essential for cellular homeostasis. Mol Cell. 2016;62(6):491-506.

16. Farhan $\mathrm{H}$, Kundu M, Ferro-Novick S. The link between autophagy and secretion: a story of multitasking proteins. Mol Biol Cell. 2017:28(9):1161-4.

17. Gietz RD, Schiestl RH. Large-scale high-efficiency yeast transformation using the LiAc/SS carrier DNA/PEG method. Nat Protoc. 2007;2(1):38-41.

18. Lobs A, Engel R, Schwartz C, Flores A, Wheeldon I. CRISPR-Cas9-enabled genetic disruptions for understanding ethanol and ethyl acetate biosynthesis in Kluyveromyces marxianus. Biotechnol Biofuels. 2017;10:164. 
19. Zhang S, Ma X, Pei X, Liu J, Shao H, Wu Z. A practical high-throughput screening system for feruloyl esterases: substrate design and evaluation. J Mol Catal B-Enzym. 2012;74(1-2):36-40.

20. Chang L, Ding M, Bao L, Chen Y, Zhou J, Lu H. Characterization of a bifunctional xylanase/endoglucanase from yak rumen microorganisms. Appl Microbiol Biotechnol. 2011;90(6):1933-42.

21. Xue H, Zhou J, You C, Huang Q, Lu H. Amino acid substitutions in the $\mathrm{N}$-terminus, cord and alpha-helix domains improved the thermostability of a family 11 xylanase XynR8. J Ind Microbiol Biotechnol. 2012;39(9):1279-88.

22. Kabeya Y, Mizushima N, Uero T, Yamamoto A, Kirisako T, Noda T, Kominami E, Ohsumi Y, Yoshimori T. LC3, a mammalian homologue of yeast Apg8p, is localized in autophagosome membranes after processing. EMBO J. 2000;19(21):5720-8.

23. Yamamoto H, Shima T, Yamaguchi M, Mochizuki Y, Hoshida H, Kakuta S, Kondo-Kakuta C, Noda NN, Inagaki F, Itoh T, et al. The thermotolerant yeast Kluyveromyces marxianus is a useful organism for structural and biochemical studies of autophagy. J Biol Chem. 2015;290(49):29476-506.

24. Klionsky DJ, Abdelmohsen K, Abe A, Abedin MJ, Abeliovich H, Arozena AA, Adachi H, Adams CM, Adams PD, Adeli K, et al. Guidelines for the use and interpretation of assays for monitoring autophagy (3rd edition). Autophagy. 2016;12(1):1-222.
25. Chen S, Cai H, Park S, Menon S, Jackson CL, Ferro-Novick S. Trs65p, a subunit of the Ypt1p GEF TRAPPII, interacts with the Arf1p exchange factor Gea2p to facilitate COPI-mediated vesicle traffic. Mol Biol Cell. 2011;22(19):3634-44.

26. Brandizzi F, Barlowe C. Organization of the ER-Golgi interface for membrane traffic control. Nat Rev Mol Cell Biol. 2013;14(6):382-92.

27. Travers KJ, Patil CK, Wodicka L, Lockhart DJ, Weissman JS, Walter P. Functional and genomic analyses reveal an essential coordination between the unfolded protein response and ER-associated degradation. Cell. 2000;101(3):249-58.

28. van Leeuwen W, van der Krift F, Rabouille C. Modulation of the secretory pathway by amino-acid starvation. J Cell Biol. 2018;217(7):2261-71.

29. Stadel D, Millarte $V$, Tillmann KD, Huber J, Tamin-Yecheskel B, Akutsu $M$, Demishtein A, Ben-Zeev B, Anikster Y, Perez F, et al. TECPR2 cooperates with $\mathrm{LC} 3 \mathrm{C}$ to regulate COPII-dependent ER export. Mol Cell. 2015;60(1):89-104

30. Papinski D, Schuschnig M, Reiter W, Wilhelm L, Barnes CA, Maiolica A, Hansmann I, Pfaffenwimmer T, Kijanska M, Stoffel I, et al. Early steps in autophagy depend on direct phosphorylation of Atg9 by the Atg1 kinase. Mol Cell. 2014;53(3):471-83.
Ready to submit your research? Choose BMC and benefit from:

- fast, convenient online submission

- thorough peer review by experienced researchers in your field

- rapid publication on acceptance

- support for research data, including large and complex data types

- gold Open Access which fosters wider collaboration and increased citations

- maximum visibility for your research: over 100M website views per year

At BMC, research is always in progress.

Learn more biomedcentral.com/submissions 